\title{
Unilateral Aplasia of the Submandibular Gland with Multiple Calcified Cervical Lymph Nodes: A Case Report and Review of the Litarutre
}

\author{
Aydan Acikgoz, ${ }^{1}$ Bora Ozden, ${ }^{2}$ and Muzaffer Elmalı ${ }^{3}$ \\ ${ }^{1}$ Deparment of Oral Diagnosis and Radiology, Faculty of Dentistry, Ondokuz Mayıs University, Samsun, Turkey \\ ${ }^{2}$ Department of Maxillofacial Surgery, Faculty of Dentistry, Ondokuz Mayıs University, Samsun, Turkey \\ ${ }^{3}$ Department of Radiology, Medicine Faculty, Ondokuz Mayıs University, Samsun, Turkey
}

Correspondence should be addressed to Aydan Acikgoz, aacikgoz@omu.edu.tr

Received 21 October 2009; Revised 25 November 2009; Accepted 13 December 2009

Copyright (C) 2010 Aydan Acikgoz et al. This is an open access article distributed under the Creative Commons Attribution License, which permits unrestricted use, distribution, and reproduction in any medium, provided the original work is properly cited.

The congenital absence of major salivary glands and nodal calcifications are both extremely rare disorders. We discuss a 67-yearold female patient with unilateral aplasia of the right submandibular gland and hypoplasia of the left submadibular gland, and the simultaneous presence of multiple calcified lymph nodes that were incidentally detected by panoramic radiography and computed tomography.

\section{Introduction}

The congenital aplasia or agenesis of one or more of the major salivary glands is an uncommon disorder. Any of the glands may be involved; however, the absence of all four major salivary glands is the most frequently encountered pattern [1-3]. Unilateral aplasia of submandibular gland is an extremely rare disorder; only 15 cases have been reported in the medical literature to date [4-16]. Salivary gland aplasia may ocur in isolation or it may be associated with other ectodermal defects [1, 17-21]. Patients may be asymptomatic $[4,5,14,22,23]$ or may suffer xerostomia, dysphagia, taste alterations, oral burning, or extensive dental caries $[1,2,10$, $15,24,25]$.

Nodal calcifications in the neck are uncommon, occuring in only $1 \%$ of enlarged nodes [26]. They are mostly associated with benign inflammatory or infectious diseases [2630]. Less frequently, this condition may be associated with malignant diseases $[31,32]$. In the head and neck region, the most commonly involved nodes are the submandibular and cervical nodes; when calcified these nodes are generally asymptomatic.

This paper presents a case of unilateral aplasia of the right submandibular gland and hypoplasia of the left submadibular gland, and the synchronous presence of multiple calcified lymph nodes that were incidentally detected by panoramic radiography and computed tomography (CT) in an elderly dental patient.

\section{Case}

A 67-year-old female patient was referred to the oral diagnosis and radiology department after suffering from periodontal problems and difficulty using her prosthetics, which she had had for more than ten years. A review of her medical history revealed that she had a ten-year history of hypertension and her right kidney had been removed three years previously due to kidney deficiency. She was using antihypertensive agents regularly and had been taking calcium supplements for osteoporosis for three years. At the initial intraoral examination, crown restorations were detected in the maxillary right first premolar and molar, left first premolar, mandibular right first premolar and molar, and left canine tooth; however, tissue compability had broken down due to gingival recession and periodontal disease. The tissue integrity and occlusal relationships of the partial prosthetics were also poor. An extraoral clinical examination by bimanual palpation revealed firm, painless, movable nodules in both the submandibular and cervical regions on the right and left sides. Panoramic radiography revealed severe bone loss in both the maxilla and the mandible, and a residual cyst 


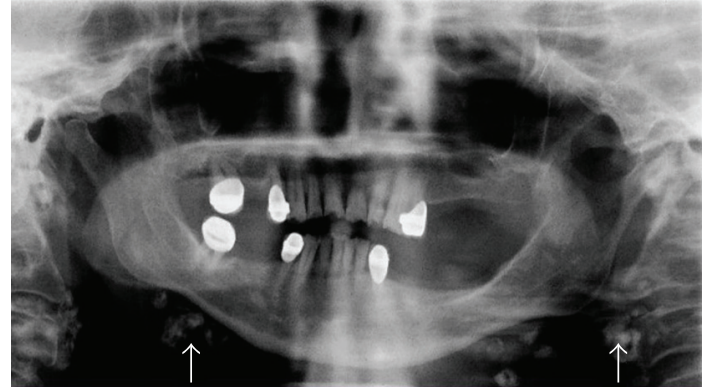

FIGURE 1: Several calcified lymph nodes are seen bilaterally on the panoramic radiograph.

was seen in the left maxillary premolar region. Of interest on the radiograph were several massive, irregularly shaped radio-opaque and radiolucent dystrofic calcific lesions. These lesions were bilateral and localized to the submandibular and cervical regions (Figure 1). Later, CT was performed for further investigations, and the region was scanned through the neck in 3-mm slices after contrast medium was administered intravenously. The CT scan revealed multiple, well-circumscribed calcified lymph nodes in the bilateral jugular areas, posterior cervical chains, and supraclavicular areas (Figures 3a and 3b). There was no adenopathy within the neck. The nasopharynx, oropharynx, pharyngeal region, arterial vascular structures in the neck, and bilateral parotid glands were normal in appearance. The CT scan also revealed that the submandibular gland was absent on the right side, and atrophic (smaller than $1 \mathrm{~cm}$ diameter) on the left side (Figure 2). A second intraoral examination did not find any evidence of the submandibular glands. The oral mucosa was wet, and no additional anomalies were present.

\section{Discussion}

This Paper describes a patient with two discrete, unusual conditions: unilateral aplasia of the submandibular gland and multiple calcified cervical lymph nodes; these findings were first discovered incidentally by panoramic radiography and CT.

Major salivary gland aplasia is a relatively rare disorder. The cause is unknown, although it may be the result of disturbances during early fetal development $[4,5,8$, $9,12,14,22]$. The four major glands are most often affected, and the parotid gland is more commonly affected than the submandibular glands $[1-3,14,21]$. Unilateral submandibular gland aplasia was first reported by Ylmaz in 1894 [4]. Since then, to the best of our knowledge, 15 more cases of unilateral submandibular gland aplasia have been reported in the medical literature; our case is the sixteenth (Table 1).

There are not enough reported cases of salivary gland aplasia to allow generalizations to be made, and the cause is unknown. However, in $75 \%$ of the reported cases, the aplasia occurred on the righthand side, as in our case. Salivary gland aplasia is frequently associated with other congenital defects, such as lacrimal gland agenesis, absence of lacrimal puncta,
TABle 1: Previously reported cases of congenital unilateral aplasia of submandibular gland.

\begin{tabular}{lcc}
\hline Author & Year & Side \\
\hline (1)Yılmaz et al. [4] & 1894 & Right \\
(2) Abdel-Dayem [16] & 1978 & Left \\
(3) Kubo et al. [6] & 1990 & Right \\
(4) Garcia-Consuegra et al. [7] & 1999 & Left \\
(5) Yllmaz et al. [4] & 2002 & Right \\
(6) Roh [8] & 2006 & Right \\
(7) Srinivasan et al. [5] & 2006 & Right \\
(8) Suzuki et al. [13] & 2007 & Right \\
(9) Shipchandler and Lorenz [12] & 2008 & Left \\
(10) Koo et al. [9] & 2009 & Left (case 1) \\
& & Right (case 1) \\
(12) Gupta et al. [11] & 2009 & Right \\
(13) Yanir et al. [14] & 2009 & Right \\
(14) Yılmaz et al. [15] & 2009 & Right \\
(15) Gallego et al. [10] & 2009 & Right \\
(16)Acikgoz et al. (present case) & 2009 & Right \\
\hline
\end{tabular}

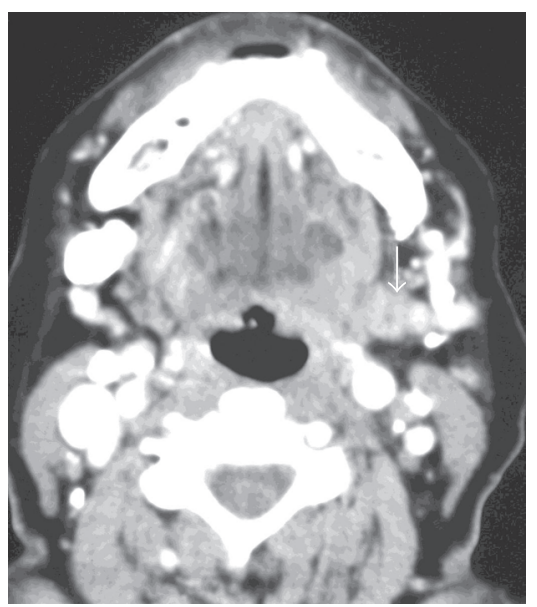

FIgURE 2: Axial cervical CT image reveals absece of the right submandibular gland.

orbital abnormalities, ectodermal dysplasia, and cleft lip and palate $[1,17-21]$. Less frequently, it appears as an isolated phenomenon $[2-5,7-10]$. In the present case, aplasia was an isolated defect, and not associated with other congenital disorders. However, in a review of the literature, none of the reported cases of unilateral submandibular gland aplasia were accompanied by other developmental anomalies [4, $7,8]$. We think that the simultaneous presence of multiple calcified lymph nodes in the neck region was a chance occurence. This condition has not been described previously in the literature.

Patients with salivary gland aplasia may suffer from xerostomia, dysphagia, taste alterations, oral burning, extensive demineralization and/or dental caries, severe periodontal disease, and difficulty using prosthetics $[1-3,10,15,24,25]$. However, these symptoms depend 


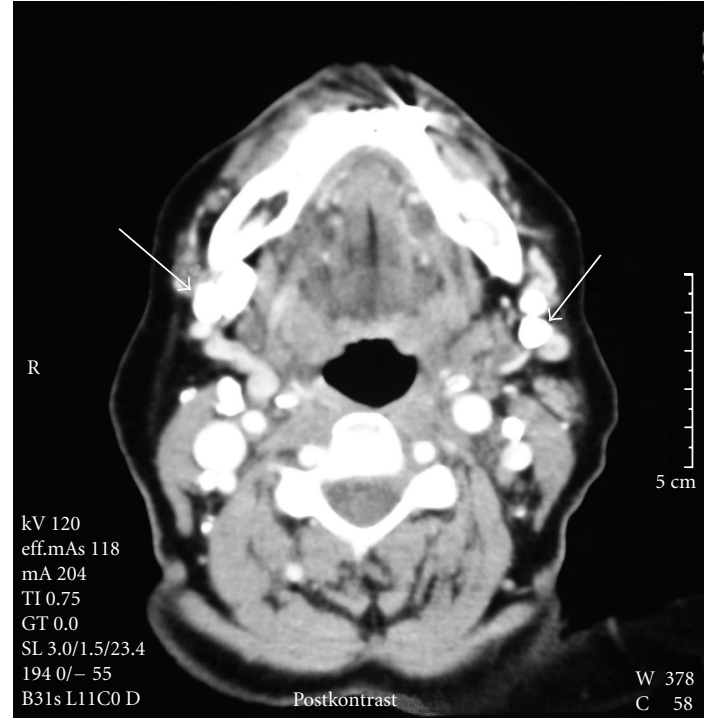

(a) Axial section of the postcontrast CT scans of the head and neck showing submandibular lymph node calcifications (Level IB).

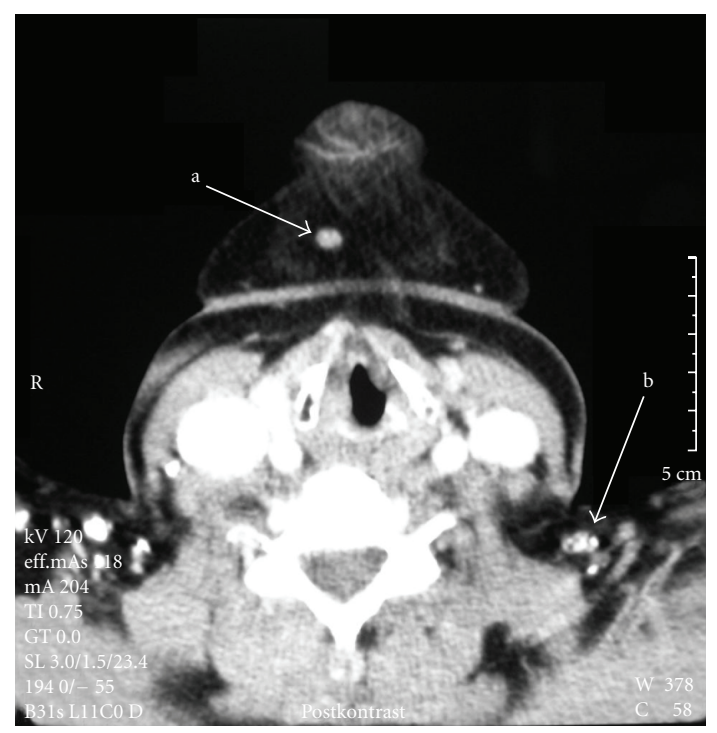

(b) Axial section of the postcontrast CT scans of the head and neck showing submandibular and submental lymph node calcifications.

FiguRe 3

upon the number of absent salivary glands. With partial agenesis of the major salivary glands, symptoms may not be significiant; thus, most of the previously reported cases of unilateral submandibular gland aplasia were asymptomatic and incidentally encountered during imaging studies $[1,2,8,9]$. In four cases, compensatory sublingual hypertrophy was the presenting symptom $[5,14,15,22]$. In the case reported here, the patient was asymptomatic. As discussed by Yllmaz et al. [4], Srinivasan et al. [5], Roh [8], Mathison and Hudgins [22], and Ahmed et al. [23], there are few reports of symptoms because the aplasia is confined to one gland only, and the secretions of other normal glands or compansatory hypertrophy of the sublingual glands compensates for it. In addition to CT, ultrasonography, scintigraphy, and magnetic resonance imaging have also been used to reveal gland aplasia $[1-5,13,21,23]$.

Nodal calcification in the neck is a rare condition. In a retrospective study, Eisenkraft and Som [26] monitored 2,300 neck-region CT scans and found that the prevalence of nodal calcifications was $1 \%$. They are mostly associated with benign conditions, such as tuberculosis, histoplasmosis, sinus histiocytosis, actinomycosis, hemangioma phleboliths, and systemic or localized amyloidosis [27-30, 33-38]. Although tuberculosis is commonly thought to be causative, calcification during cervical adenopathy appears to be uncommon in tuberculosis [26]. Baskota et al. [35] reported that in patients with tuberculous cervical lympadenitis, the majority of the nodes are unilateral; of these, only one group of lymph nodes is usually involved. It was also reported that calcification in tuberculous neck nodes is much less common than calcification in nodes elsewhere in the body [31]. The case presented here is very unusual because the lesions were in jugular, supraclavicular, and posterior cervical lymph node chains, and were both bilateral and multiple.

Infrequently, nodal calcification may be associated with malignant diseases. It was reported that the most common neoplastic cause of nodal calcification in the neck is thyroid tumors [31, 32]. However, Gormly and Glastonbury [31] also reported a case of calcified submandibular nodal metastasis resulting from squamous cell carcinoma of the lip, and head -neck squamous cell carcinomas must be considered during differential diagnosis.

Other soft tissue calcifications in the neck region that mimic lymph node calcifications and are superimposed on panoramic radiographs include tonsilloliths, calcified blood vessels, osteoma cutis, sialolith, myositis ossificians, and dystrophic calcifications [27, 29, 30]. They are usually asymptomatic and first discovered as an incidental finding on panoramic or lateral oblique radiographs in dentistry. Some may be radiographically projected over the mandibular bone and are thus misdiagnosed as osseous lesions. Identification of soft tissue calcifications is difficult when relying on panoramic or lateral oblique radiographs alone. Although $\mathrm{CT}$ is an excellent imaging approach for revealing calcified lymph nodes, it does not allow for differentiation between benign and malignant lesions [26]. Therefore, biopsy is obligatory in almost all cases for diagnostic purposes.

In conclusion, unilateral submandibular gland aplasia and nodal calcification in the neck are both very rare conditions. However, the true incidence of unilateral submandibular gland aplasia is difficult to determine because the condition is often asymptomatic. Early diagnosis of this anomaly is essential to minimize tooth decay, periodontal disease, and swallowing difficulties. Cervical node calcification may be associated with benign or malignant conditions. However, CT does not allow for differentiation between benign and malignant lesions; thus, further investigations must be carried out. Because the patient in the present case did not consent to further examinations due to the absence 
of any symptoms associated with the calcified lesions, we do not know the etiology of her nodal calcifications.

\section{References}

[1] S.-Y. Kwon, E.-J. Jung, S.-H. Kim, and T.-K. Kim, "A case of major salivary gland agenesis," Acta Oto-Laryngologica, vol. 126, no. 2, pp. 219-222, 2006.

[2] L. Mandel, "An unusual pattern of dental damage with salivary gland aplasia," Journal of the American Dental Association, vol. 137, no. 7, pp. 984-989, 2006.

[3] N. Heath, I. Macleod, and R. Pearce, "Major salivary gland agenesis in a young child: consequences for oral health," International Journal of Paediatric Dentistry, vol. 16, no. 6, pp. 431-434, 2006.

[4] M. Yılmaz, A. Yücel, S. Dereköy, and A. Altuntaş, "Unilateral aplasia of the submandibular gland," European Archives of OtoRhino-Laryngology, vol. 259, no. 10, pp. 554-556, 2002.

[5] A. Srinivasan, J. S. Moyer, and S. K. Mukherji, "Unilateral submandibular gland aplasia associated with ipsilateral sublingual gland hypertrophy," American Journal of Neuroradiology, vol. 27, no. 10, pp. 2214-2216, 2006.

[6] S. Kubo, K. Abe, T. Ureshino, and M. Oka, "Aplasia of the submandibular gland: a case report," Journal of CranioMaxillo-Facial Surgery, vol. 18, no. 3, pp. 119-121, 1990.

[7] L. Garcia-Consuegra, L. J. Gutierrez, J. M. A. Castro, and J. F. Granado, "Congenital unilateral absence of the submandibular gland," Journal of Oral and Maxillofacial Surgery, vol. 57, no. 3, pp. 344-346, 1999.

[8] J.-L. Roh, "Unilateral submandibular gland aplasia: an isolated phenomenon of early fetal development," Otolaryngology, vol. 135, no. 2, pp. 332-334, 2006.

[9] B. S. Koo, S. W. Lee, Y. M. Lee, J. D. Lee, and Y. W. Koh, "Sialolithiasis in a stump of Wharton's duct of an aplastic unilateral submandibular gland," International Journal of Oral and Maxillofacial Surgery, vol. 38, no. 1, pp. 93-95, 2009.

[10] L. Gallego, L. Junquera, P. Cuesta, and P. Rosado, "Symptomatic unilateral submandibular gland aplasia," British Journal of Oral and Maxillofacial Surgery, vol. 47, no. 3, p. 243, 2009.

[11] N. Gupta, E. Palacios, and S. Barry, "Unilateral submandibular gland aplasia: a rare phenomenon," Ear, Nose and Throat Journal, vol. 88, no. 3, pp. 818-820, 2009.

[12] T. Z. Shipchandler and R. R. Lorenz, "Unilateral submandibular gland aplasia masquerading as cancer nodal metastasis," American Journal of Otolaryngology, vol. 29, no. 6, pp. 432434, 2008.

[13] M. Suzuki, Y. Hamada, A. Hamada, et al., "Congenital unilateral aplasia of the submandibular gland: a case report and literature review," Asian Journal of Oral and Maxillofacial Surgery, vol. 19, no. 2, pp. 122-125, 2007.

[14] Y. Yanir, G. Fleiman, and R. Cohen-Kerem, "Aplasia of the submandibular gland with compensatory sublingual gland hypertrophy: a case report," International Journal of Pediatric Otorhinolaryngology Extra, vol. 4, no. 2, pp. 77-79, 2009.

[15] M. Yilmaz, E. Karaman, H. Isildak, O. Enver, and F. Kilic, "Symptomatic unilateral submandibular gland aplasia associated with ipsilateral sublingual gland hypertrophy," to appear in Dysphagia.

[16] H. M. Abdel-Dayem, "Congenital absenceof submaxillary gland detected on 99mTc-pertechnetate thyroid imaging," Clinical Nuclear Medicine, vol. 3, no. 11, p. 442, 1978.
[17] M. Yild $\imath$ rım, M. F. Oktay, C. Ozmen, I. Yavuz, and I. Topcu, "Reveal by biotechnological equipment to the bilateral nonfunctional submandibular glands in ectodermal dysplasia," Biotechnology and Biotechnological Equipment, vol. 22, no. 4, pp. 1005-1007, 2008.

[18] P. Singh and S. Warnakulasuriya, "Aplasia of submandibular salivary glands associated with ectodermal dysplasia," Journal of Oral Pathology and Medicine, vol. 33, no. 10, pp. 634-636, 2004.

[19] A. P. S. Ferreira, R. S. Gomez, W. H. Castro, N. S. Calixto, R. A. P. Silva, and M. J. B. Aguiar, "Congenital absence of lacrimal puncta and salivary glands: report of a brazilian family and review," American Journal of Medical Genetics, vol. 94, no. 1, pp. 32-34, 2000.

[20] H. Nordgarden, B. Mork-Knutsen, K. P. Hammerlund, and K. Storhaug, "Salivary gland hypoplasia and aplasia is not so uncommon in persons with oligodontia and ectodermal dysplasias?" Europian Cells and Materials, vol. 14, no. 5, supplement 2, p. 115, 2007.

[21] C. Matsuda, Y. Matsui, K. Ohno, and K.-I. Michi, "Salivary gland aplasia with cleft lip and palate: a case report and review of the literature," Oral Surgery, Oral Medicine, Oral Pathology, Oral Radiology, and Endodontics, vol. 87, no. 5, pp. 594-599, 1999.

[22] C. C. Mathison and P. A. Hudgins, "Bilateral submandibular gland aplasia with hypertrophy of sublingual glands," Otolaryngology, vol. 138, no. 1, pp. 119-120, 2008.

[23] M. Ahmed, M. Strauss, A. Kassaie, V. Shotelersuk, and R. DeGuzman, "Bilateral submandibular gland aplasia with clinico-radiological mass due to prolapsing sublingual salivary tissue through mylohyoid boutonniere: a case report and review," Dentomaxillofacial Radiology, vol. 38, no. 2, pp. 121124, 2009.

[24] N. Al-Talabani, I. S. Gataa, and S. A. Latteef, "Bilateral agenesis of parotid salivary glands, an extremely rare condition: report of a case and review of literature," Oral Surgery, Oral Medicine, Oral Pathology, Oral Radiology and Endodontology, vol. 105, no. 3, pp. e73-e75, 2008.

[25] M. S. Fracaro, V. M. Linnett, K. B. Hallett, and N. W. Savage, "Submandibular gland aplasia and progressive dental caries: a case report," Australian Dental Journal, vol. 47, no. 4, pp. 347350, 2002.

[26] B. L. Eisenkraft and P. M. Som, "The spectrum of benign and malignant etiologies of cervical node calcification," American Journal of Roentgenology, vol. 172, no. 5, pp. 1433-1437, 1999.

[27] A. R. Silvers, P. M. Som, and R. J. Meyer, "Egg shell nodal calcification in a patient with sinus histiocytosis with massive lymphadenopathy treated with interferon," American Journal of Neuroradiology, vol. 17, no. 2, pp. 361-363, 1996.

[28] L. Mandel, "Tuberculous cervical node calcifications mimicking sialolithiasis: a case report," Journal of Oral and Maxillofacial Surgery, vol. 64, no. 9, pp. 1439-1442, 2006.

[29] M. I. Kara, D. Yeler, H. Yeler, and S. Ay, "Panoramic radiographic appearance of massive calcification of tuberculous lymph nodes," Journal of Contemporary Dental Practice, vol. 9, no. 6, pp. 108-114, 2008.

[30] M. Keberle and S. Robinson, "Physiologic and pathologic calcifications and ossifications in the face and neck," European Radiology, vol. 17, no. 8, pp. 2103-2111, 2007.

[31] K. Gormly and C. M. Glastonbury, "Calcified nodal metastasis from squamous cell carcinoma of the head and neck," Australasian Radiology, vol. 48, no. 2, pp. 240-242, 2004. 
[32] F. Pombo, E. Rodriquez, J. I. Cao, and C. Martinez-Isla, "Cervical lymph node metastases of medullary thyroid carcinoma: CT findings," European Radiology, vol. 7, no. 1, pp. 99-101, 1997.

[33] L. Mandel and F. Surattanont, "Clinical and imaging diagnoses of intramuscular hemangiomas: the wattle sign and case reports," Journal of Oral and Maxillofacial Surgery, vol. 62, no. 6, pp. 754-758, 2004.

[34] A. D. Gean-Marton, C. F. E. Kirsch, L. G. Vezina, and A. L. Weber, "Focal amyloidosis of the head and neck: evaluation with CT and MR imaging," Radiology, vol. 181, no. 2, pp. 521$525,1991$.

[35] D. K. Baskota, R. Prasad, B. K. Sinha, and R. C. M. Amatya, "Distribution of lymph nodes in the neck in cases of tuberculous cervical lymphadenitis," Acta Oto-Laryngologica, vol. 124, no. 9, pp. 1095-1098, 2004.

[36] B. H. Gross, H. J. Schneider, and A. V. Proto, "Eggshell calcification of lymph nodes: an update," American Journal of Roentgenology, vol. 135, no. 6, pp. 1265-1268, 1980.

[37] M. D. de Moura, D. F. Madureira, L. C. Noman-Ferreira, E. N. Abdo, E. G. de Aguiar, and A. R. Freire, "Tonsillolith: a report of three clinical cases," Medicina Oral, Patología Oral y Cirugía Bucal, vol. 12, no. 2, pp. E130-133, 2007.

[38] S. Ram, C. Huat Siar, S. Mazlipah Ismail, and N. Prepageran, "Pseudo bilateral tonsilloliths: a case report and review of the literature," Oral Surgery, Oral Medicine, Oral Pathology, Oral Radiology and Endodontology, vol. 98, no. 1, pp. 110-114, 2004. 